\title{
Human predation along Apulian rocky coasts (SE Italy): desertification caused by Lithophaga lithophaga (Mollusca) fisheries
}

\author{
G. Fanelli ${ }^{1}$, S. Piraino ${ }^{2}$, G. Belmonte ${ }^{1}$, S. Geraci ${ }^{3}$, F. Boero ${ }^{1, *}$ \\ ${ }^{1}$ Dipartimento di Biologia, Stazione di Biologia Marina di Porto Cesareo, Università di Lecce, I-73100 Lecce, Italy \\ ${ }^{2}$ Dipartimento di Zoologia, Università di Napoli, Via Mezzocannone 8, I-80134 Napoli, Italy \\ ${ }^{3}$ Istituto Talassografico 'A. Cerruti'- CNR, Via Roma 3, I-74100 Taranto, Italy
}

\begin{abstract}
The date mussel Lithophaga lithophaga is a Mediterranean boring mollusc living in calcareous rocks. Its populations are intensely exploited by SCUBA divers, especially in southern Italy. Collection is carried out by demolition of the rocky substratum, so that human predation on date mussels causes the disappearance of the whole benthic community. The impact of this activity along the Apulian coast was evaluated by 2 surveys carried out by SCUBA diving inspection of the Salento peninsula. The Ionian coast of Apulia, from Taranto to Torre dell'Orso (Otranto), was surveyed in 1990 and in 1992 by 2 series of transects (from 0 to $10 \mathrm{~m}$ depth, $2 \mathrm{~km}$ from each other), covering $210 \mathrm{~km}$. Observations were transformed into an index of damage, ranging from 0 (no damage) to 1 (complete desertification). $159 \mathrm{~km}$ of the inspected coast are rocky. The first survey (1990) allowed us to estimate that a total of $44 \mathrm{~km}$ was heavily affected by this human activity (the index of damage ranging between 0.5 and 1), whereas the second survey showed heavy damage along a total of $59 \mathrm{~km}$. This increase in length was accompanied by a high increase in the index of damage along parts of coast that were less intensely exploited in 1990 than in 1992. The second survey (1992) was extended to $90 \mathrm{~km}$ of the Adriatic coast of Apulia (from Otranto to Torre S. Sabina, Brindisi), with $47 \mathrm{~km}$ of rocky coast and a total of $10 \mathrm{~km}$ heavily affected by date mussel fishery. Date mussel collection is one of the most destructive human activities along the Apulian coast and it has long-term effects because sea urchin grazing probably prevents recolonization of barren areas. Rarefaction of the resource due to overexploitation and habitat destruction caused rapid 'evolution' of the techniques of predation, with an increase in searching efficiency achieved by the use of underwater vehicles. Similar impacts of date mussel collection have been recorded in other parts of the Italian coast, especially Campania and Sardinia, and it is possible that such situations are common, but still undetected, in other areas of the Mediterranean.
\end{abstract}

KEY WORDS: Lithophaga lithophaga - Fisheries - Desertification - Survey - Mediterranean Sea

\section{INTRODUCTION}

There is a great difference in the way humans interact with terrestrial and aquatic habitats. On land, most human activities are visually oriented and their effects are also often immediately visible, as is the case with logging, cultivation, building and so on. In the sea, human activities are usually mediated by surface-operated machines. The invention of SCUBA made visually oriented underwater activities easy, with the possibility of more precise target identification. Precious coral fish-

\footnotetext{
-Addressee for correspondence
}

eries by SCUBA divers, for instance, concentrate the effort towards corals, whereas collection with trawlers operated from the surface causes destruction of many other species. A big difference between land- and seabased direct human activities, however, persists: on land, physical destruction of habitats is immediately evident to everybody, often causing strong negative reactions against its agents, whereas destruction of marine environments could remain undetected for some time and thus not directly linked to its cause.

Only recently, for instance, has tourist SCUBA diving been perceived as a source of problems in the management of coral reefs, due to overcrowding and consequent damaging of coral formations by direct impact 
with humans (Hawkins \& Roberts 1993). In the Mediterranean Sea, SCUBA diving is a widespread technique and is extensively used for many purposes, including date mussel collection.

The European date mussel Lithophaga lithophaga (L.) is a rock-boring bivalve mollusc widespread along the whole Mediterranean coast (Fisher et al. 1987). It lives inside galleries bored in calcareous rock by glandular secretions (see Morton \& Scott 1980). Date mussels inhabit shallow waters, reaching their maximum densities (up to 300 ind. $\mathrm{m}^{-2}$ ) in the rocks within $5 \mathrm{~m}$ depth (see Hrs-Brenko et al. 1991); they can be found, however, up to $20-25 \mathrm{~m}$ depth. Rock inclination seems to be important for these mytilids, which prefer vertical walls; also the orientation of the rocky walls seems to play a role in the choice of the optimal settling site (Kleeman 1974).

Date mussel growth is extremely slow because it is interrupted by resting pcriods. Growth is relatively faster in young stages, characterized by more frequent growth periods (Kleeman 1973). According to Pierotti et al. (1966) date mussels reach the minimal commercial size of $5 \mathrm{~cm}$ in 15 to $20 \mathrm{yr}$, whereas Klecman (1973) reported such size as being reached in at least $35 \mathrm{yr}$.

In the Mediterranean area, Lithophaga lithophaga is actively collected by SCUBA divers who break the rocks with special sledgehammers to expose the molluscs. Russo \& Cicogna (1992) surveyed the available knowledge about the Italian situation and reported that an experienced diver can collect 15 to $25 \mathrm{~kg}$ of date mussels in a dive of 3 to $4 \mathrm{hr}$. They estimated that the activity of 30 fishermen along the Penisola Sorrentina (the peninsula dividing the Gulfs of Naples and Salerno, Tyrrhenian Sea) can reach 81 to $135 \mathrm{t}$ of date mussels per year. Detailed studies of population dynamics of this species are lacking, but it is highly probable that the recovery of the exploited stocks is rather slow. Moreover, such fishing activity has an even greater impact on the benthic communities covering the rocks inhabited by date mussels (Fig. 1). All sessile organisms are eradicated during date mussel collection, and the exploited rocks remain completely bare (Russo \& Cicogna 1991).

Owing to the complete destruction of benthic communities and to the dismantling of rocky substrata, Italian law has prohibited collection and sale of date mussels since 1988. Unfortunately such laws did not result in a decrease of date mussel fisheries, because of the stili high demand tor the mollusc. Furthermore, the increase in price, caused by the 'risk' of collecting, encouraged even nonprofessional fishermen to start this activity as a part-time job. Lithophaga lithophaga

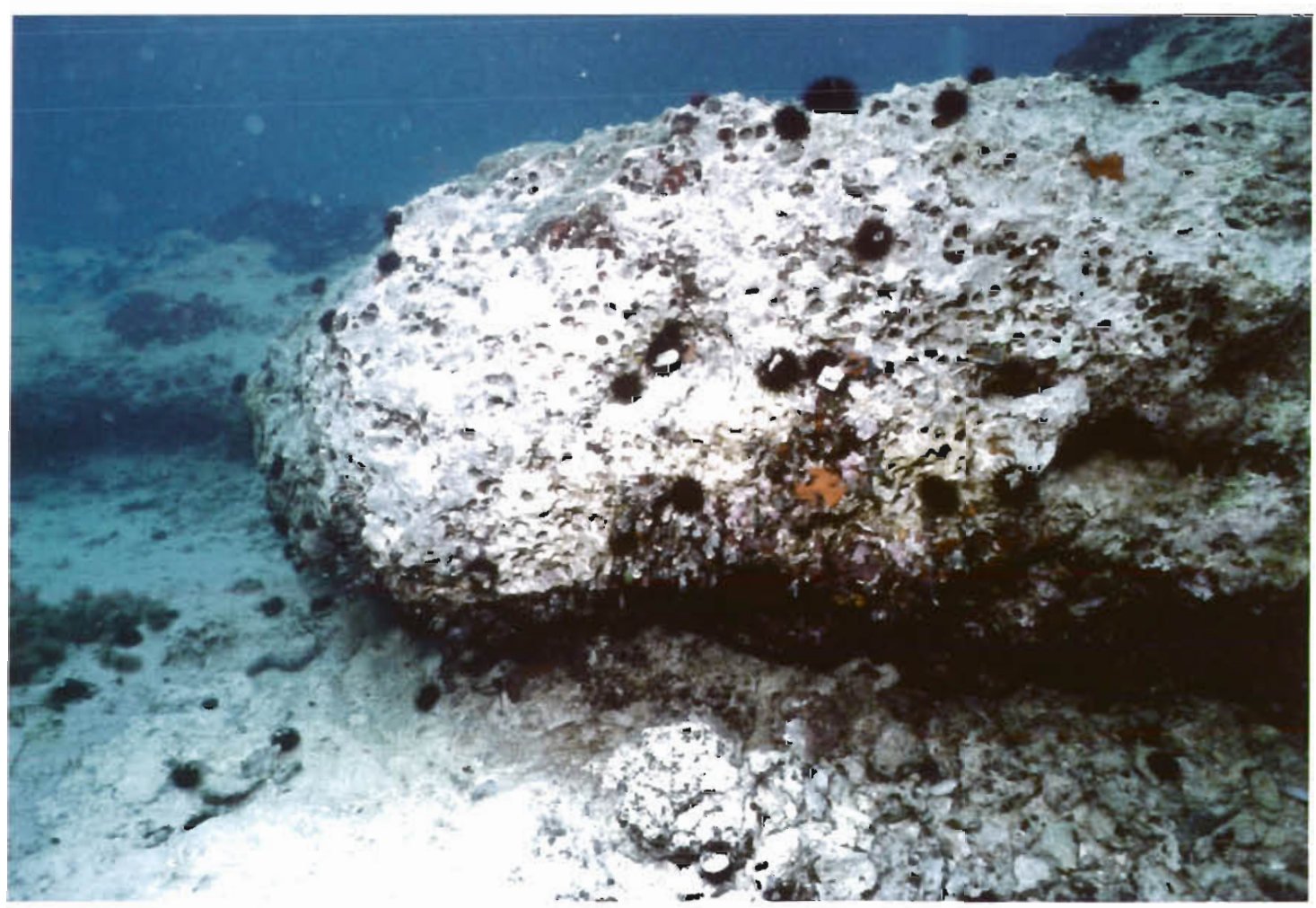

Fig. 1. Underwater photograph of a barren area caused by date mussel collection. Detritus is still evident at the base of the demolished rock 
is much appreciated for its taste along the Apulian coast, where it is collected in unquantified but presumably large amounts. For this reasons we concentrated our studies on this coast, here considered as a possible paradigm for similar situations in other areas of the Mediterranean Sea. Besides Italy, where it is intensely exploited in Apulia (this paper), Campania (Russo \& Cicogna 1992) and Sardinia (Cuccu et al. 1994), L. lithophaga is collected in other countries of the Mediterranean basin, and Fisher et al. (1987) reported an estimate of $30 \mathrm{t} \mathrm{yr}^{-1}$ for Yugoslavia. Since these fisheries are usually illegal, most of the activity escapes any attempt at quantification by official institutions and yields are underestimated.

The aim of the present study was to quantify by in situ observations the impact of such type of fishery on subtidal communities along hundreds of kilometres of coast.

Preliminary observations at several sites along the Salento peninsula (Ionian coast of Apulia, SE Italy) showed large bare areas where the sea urchins Arbacia lixula and Paracentrotus lividus were extremely abundant. Sea urchin grazing has been demonstrated as having an important impact on the development of marine benthic communities (e.g. Elner \& Vadas 1990). It appeared more and more evident that the effects of date mussel collection and the lack of recolonization, possibly due to sea urchin grazing, might represent a real environmental catastrophe.

A quantification of the environmental impact of date mussel fisheries is thus much needed, because such an underestimated activity is, in fact, a source of widespread eradication of macroscopic life from wide portions of shallow rocky coasts.

\section{MATERIALS AND METHODS}

A first survey along $210 \mathrm{~km}$ of the Apulian Ionian coastline (Fig. 2), from Taranto to Torre dell'Orso, was carried out between 4 and 15 July 1990. A total of about $159 \mathrm{~km}$ of this coast is rocky and was surveyed by 83 transects perpendicular to the shore and about $2 \mathrm{~km}$ apart from each other. These transects included 241 stations. A second survey, including also part of the Apulian Adriatic coast, was carried out between 15 and 26 June 1992 along $300 \mathrm{~km}$ of coastline, from Taranto to Torre S. Sabina, Brindisi. The additionally inspected coast from Torre dell'Orso to Torre S. Sabina is rocky for about $47 \mathrm{~km}$. The second survey consisted of 110 transects, at 409 stations. During both surveys, the sea bottom between the surface and $10 \mathrm{~m}$ depth, or up to about $300 \mathrm{~m}$ from the coastline, was examined by SCUBA diving. When possible, transects consisted of a series of stations at several depth levels $(0-1,1-3,3-5$.
$5-7,7-9$ and $9-10 \mathrm{~m}$ ). In both surveys the presence of date mussels (as living specimens or as empty galleries), and the extent and age of rock damage were directly evaluated in situ. In many cases the bottom was not steep enough to cover this depth range in $300 \mathrm{~m}$. A form was filled at each transect, recording the observations for each station. Rock damage was first evaluated by measuring size and frequency of bare patches according to a series of categories with values ranging from 0 to 7 , as described in Table 1 . For ease of analysis the original damage codings were later grouped into 4 larger 'states': no damage (values 0,1 ), low damage (values 2,3 ), medium damage (values 4,5 ), great damage (values 6, 7) (Table 1). Such states were used also for general description of surveys. Rock damage was divided into 2 categories: (1) recent, when recolonization was completely lacking and the breaks in the rocks were sharp; in such cases rock fragments still covered by sessile organisms were occasionally found on the bottom; (2) not-recent, when some traces of recolonization were apparent and the outlines of the bare patches were not sharp.

Both whole transects and single stations with no date mussels were likened to sandy shores and were not considered for damage evaluation. Transects along the surveyed coast were grouped into 5 different coastal sectors (A, B, C, D and E; see Fig. 2), according to relative affinities in bottom slope, substratum typology and date mussel presence. A sixth sector $(F)$ was considered during the second survey only.

A weighted index of damage $\left(D_{\mathrm{w}}\right)$ was calculated to relate the observed damage categories to the maximum possible damage within a 0 to 1 range of values. This was obtained by the sum of $n$ values of relative

Table 1. Damage evaluation

\begin{tabular}{|lcc|}
\hline Description & Value & State \\
\hline $\begin{array}{l}\text { A.bsent } \\
\text { Isolated small bare patches }\end{array}$ & 0 & No damage \\
$(20 \times 20 \mathrm{~cm})$ & 1 & \\
$\begin{array}{l}\text { Isolated medium bare patches } \\
(50 \times 50 \mathrm{~cm})\end{array}$ & 2 & \\
$\begin{array}{l}\text { Isolated large bare patches } \\
(1 \times 1 \mathrm{~m})\end{array}$ & 3 & Low damage \\
$\begin{array}{l}\text { Abundant small bare patches } \\
(20 \times 20 \mathrm{~cm})\end{array}$ & 4 & \\
$\begin{array}{l}\text { Abundant medium bare patches } \\
(50 \times 50 \mathrm{~cm})\end{array}$ & 5 & \\
$\begin{array}{l}\text { A.bundant large bare patches } \\
(1 \times 1 \mathrm{~m})\end{array}$ & 6 & \\
Complete desertification & 7 & \\
\hline
\end{tabular}




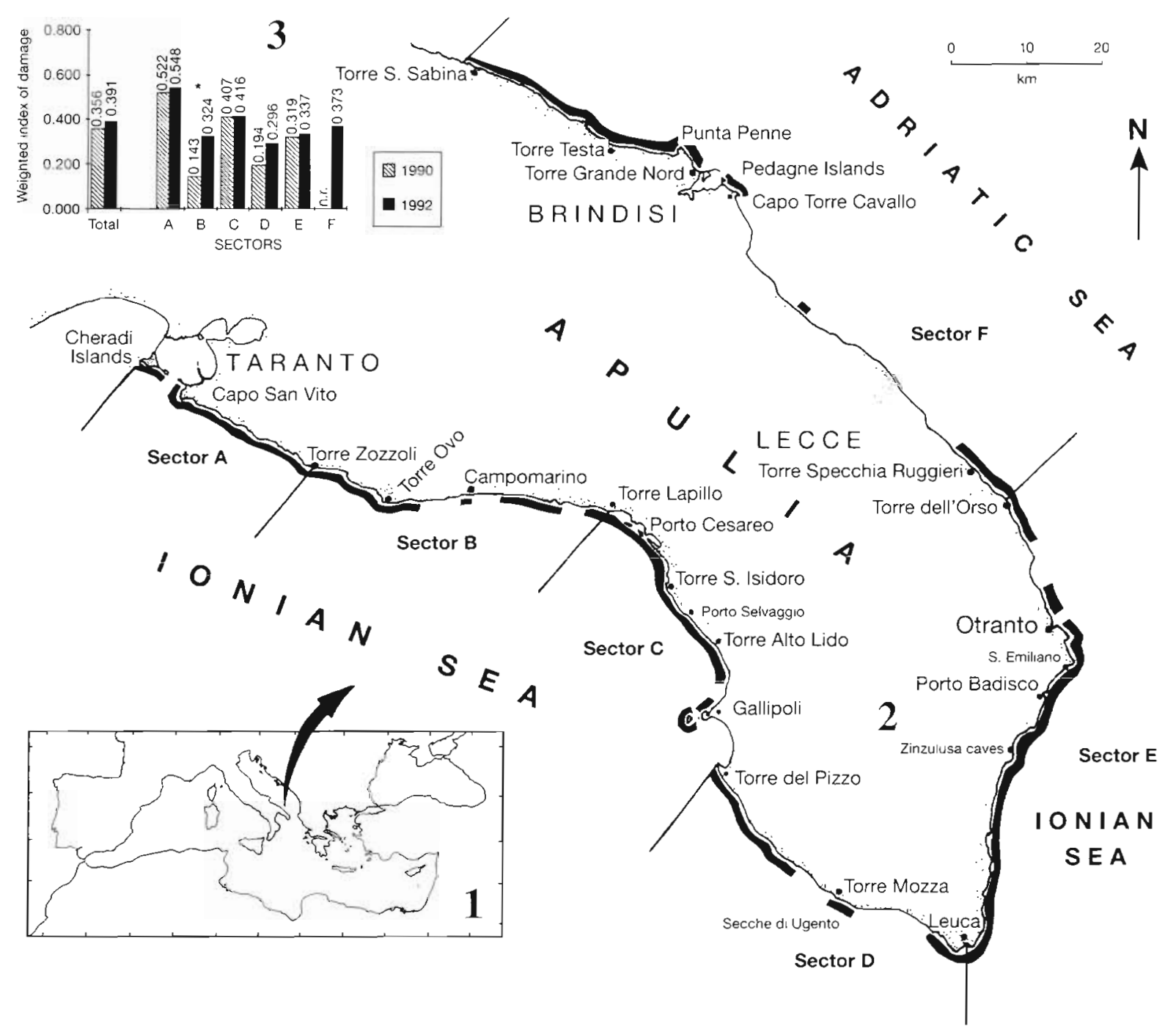

Fig. 2. (1) Position of the Salento peninsula (Apulia, Italy) in the Mediterranean region. (2) Surveyed sectors of the Salento peninsula. Solid lines represent rocky shores. (3) Values of the weighted index of damage $\left(D_{w}\right)$ for the whole coast and each sector in the 2 surveys. "Significant differences (Student's $t$-test)

damage $\left(V_{i} / V_{\max }\right.$, where $V_{1}=$ recorded value, and $V_{\max }$ $=7$ ), divided by the $n$ records:

$$
D_{\mathrm{w}}=\frac{\sum_{i=1}^{n} \frac{V_{1}}{7}}{n}
$$

The index, ranging between 0 (no damage) and 1 (complete desertification), represents the average of relative damage, allowing comparison of the 2 surveys, within and between sectors and/or transects. The $D_{\mathrm{w}}$ values at each transect were retained as representing the situation along the coast almost $1 \mathrm{~km}$ before and $1 \mathrm{~km}$ after the transect itself. Differences between the $D_{\text {w }}$ of the 2 surveys, in total and within each sector, were statistically tested by the Student's $t$-test. Data distributions were not normal, but error term distribu- tions were not statistically different within the compared samples (Kolmogorov-Smirnov test, $\mathrm{p}>0.05$ ), and sample size was large enough to allow the use of a parametric test.

The levels of dependence between the existence of damage and depth were calculated by the chi-squared test. The same test was performed to evaluate differences between 1990 and 1992 in the distribution of recent and not-recent damage.

To recognize possible trends in the impact of date mussel collection, the differences in $D_{\mathrm{w}}$ between the 1990 and 1992 surveys at 2 depth ranges 10 to 5 and 5 to $10 \mathrm{~m}$ ) for sectors $A$ to $E$ were plotted against the corresponding $D_{w}$ values for the first survey (1990) and interpolated by a second-order polynomial curve. 
Fig. 3. Cumulative representation of surveyed coast and extent of damage in the 2 surveys (sector F, from Torre dell'Orso to Torre S. Sabina, Brindisi, was not surveyed in 1990)

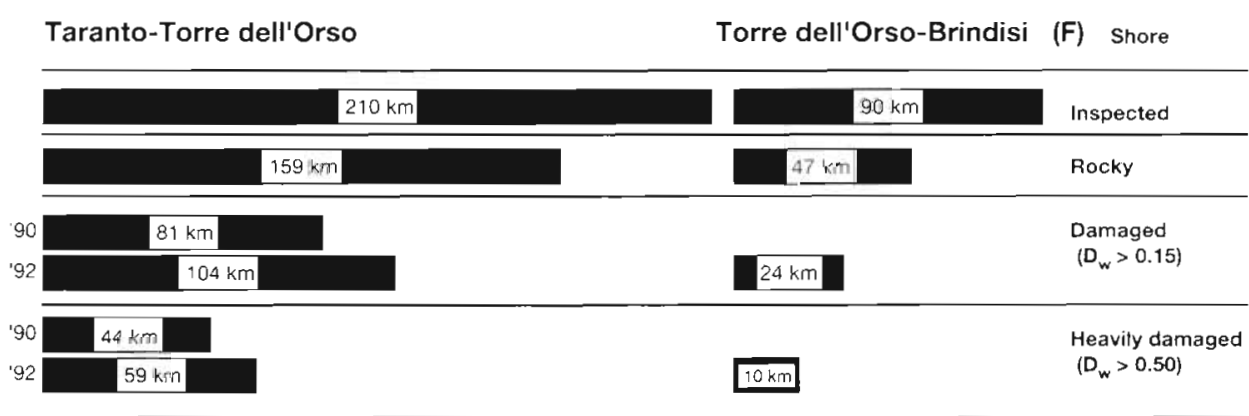

\section{RESULTS}

\section{First survey (1990)}

Half the rocky coast was affected by date mussel fisheries (81 out of $159 \mathrm{~km}$ ) and $44 \mathrm{~km}$ of it were heavily damaged (Fig. 3). D was 0.356 for the whole rocky coast (Fig. 2).

In general, damage was recorded at every considered depth range (Fig. 4), with no significant correlation of damage with depth (chi-squared test $i \mathrm{p}>0.05$ ).

Not-recent damage was recorded at $57.5 \%$ of the damaged stations.

\section{Second survey (1992)}

About $2 / 3$ of the rocky coast was affected by date mussel fisheries (128 out of $206 \mathrm{~km}$ ) and $69 \mathrm{~km}$ of it were heavily damaged (Fig. 3). $D_{w}$ was 0.389 .

Depth-damage correlation was not significant (Fig. 4) (chi-squared test; $p>0.05$ ).

Not-recent damage was recorded at $73.5 \%$ of the damaged stations.

\section{Comparison of surveys}

The observations made during the first and second survey along the same tract of Ionian coast, from Taranto to Torre dell'Orso, showed that in 1990 a total of $44 \mathrm{~km}$ was heavily affected ( $D_{w}$ ranging between 0.5 and 1), whereas in 1992 the length of the damaged coast totalled $59 \mathrm{~km}$ (Fig. 3). The values of the weighted index of damage $\left(D_{w}\right)$ were not significantly different $(0.356$ in 1990 and 0.391 in 1992; Student's t-test; $p>0.05$ ). The extent of the damage was similar in the 2 surveys and in the 2 main depth ranges considered $(0$ to 5 , 5 to $10 \mathrm{~m}$ ) (data not shown; Student's t-test; $p>0.05$ ).

The percentage of stations with not-recent damage significantly increased from 1990 to 1992 (57.5 vs 73.5\%: chi-squared; $\mathrm{p}<0.05)$.
The damage caused by date mussel fisheries was widespread, but not homogeneous, along the whole rocky shore of the studied coast. Observations on each coastal sector will be analyzed here in detail to identify patterns and scales of this phenomenon (Fig. 5).

Sector A. This is the sector where the highest $D_{w}$ values were observed: over 0.50 in both surveys and no significant difference between 1990 and 1992 (Student's t-test; $p>0.05$ ) (Fig. 2). Damaged rocks were uniformly recorded at every depth; in fact, differences between $D_{w}$ of shallower stations $(0$ to $5 \mathrm{~m})$ and deeper ones were not significant in either survey (data not shown).

Cheradi Islands to Capo San Vito (4 transects): Around the islands there are few substrata proper for

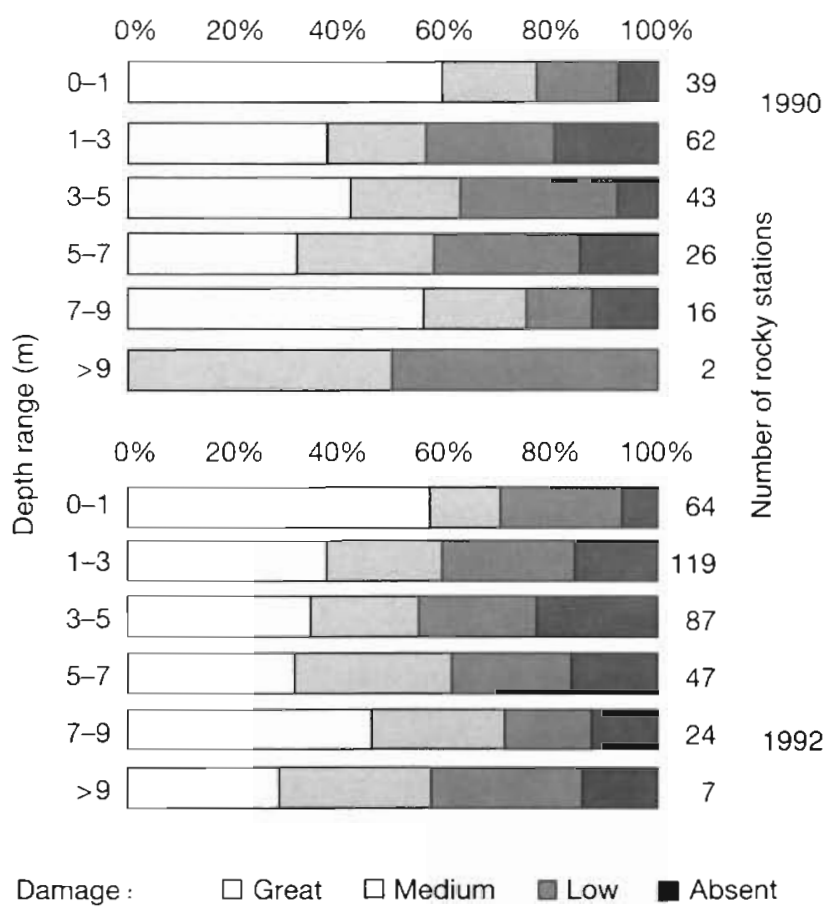

Fig. 4. Distribution of damage states in groups of rocky stations in different depth ranges 


\begin{tabular}{|c|c|c|c|c|c|}
\hline A & B & c & D & E & Shore \\
\hline $25 \mathrm{~km}$ & $39 \mathrm{~km}$ & $35 \mathrm{~km}$ & $51 \mathrm{~km}$ & $60 \mathrm{~km}$ & Inspected \\
\hline $23.5 \mathrm{~km}$ & $18.5 \mathrm{~km}$ & $29.5 \mathrm{k}$ & $33.5 \mathrm{~km}$ & $54 \mathrm{~km}$ & Rocky \\
\hline \begin{tabular}{l|l}
90 & $17.6 \mathrm{~km}$ \\
92 & $22 \mathrm{~km}$
\end{tabular} & $\begin{array}{l}3.7 \mathrm{~km} \\
10.6 \mathrm{~km}\end{array}$ & & ${ }^{4.5} \mathrm{~km}$ & $\begin{array}{r}34.1 \mathrm{~km} \\
41.7 \mathrm{~km}\end{array}$ & $\begin{array}{l}\text { Damaged } \\
\left(D_{w}>0.15\right)\end{array}$ \\
\hline \begin{tabular}{l|l}
90 & $13.2 \mathrm{~km}$ \\
92 & $13.2 \mathrm{~km}$ \\
\end{tabular} & $\begin{array}{l}3.7 \mathrm{~km} \\
5.3 \mathrm{~km}\end{array}$ & $\frac{11.5 \mathrm{~km}}{13.1 \mathrm{~km}}$ & $4.5 \mathrm{~km}$ & $11.4 \mathrm{~km}$ & $\begin{array}{l}\text { Heavily } \\
\text { damaged } \\
\left(D_{w}>0.50\right)\end{array}$ \\
\hline
\end{tabular}

Fig. 5. Cumulative representation of surveyed coast and extent of damage at each sector in the 2 surveys (sector $F$ was not surveyed in 1990; data from 1992 survey reported in Fig. 3)

date mussel settlement (large areas are covered by seagrass meadows and brown algae); isolated bare patches (damage value 1,2 ) were present on the few vertical rocks. The artificial breakwater connecting the 2 islands, a traditional area for date mussel fisheries, was highly damaged.

Cape San Vito to Torre Zozzoli (12 transects): The coast is mostly rocky, with small sandy beaches. During both surveys, all transects showed medium-high damage (most of the $D_{\mathrm{s}}$ values were $>0.50$ ), caused in many cases by recent collection. Large barren areas were recorded at all depths, in some transects starting from the intertidal bottoms.

Sector B. Torre Zozzoli to Torre Lapillo (15 transects in 1990 and 14 in 1992): Rocks are scarce, the coast is characterized by long sandy beaches. In 1990 the $D_{w}$ of this sector was 0.143 , while in 1992 it was significantly higher $\left(D_{w}=0.324\right)$ (Student's t-test; $\left.p<0.001\right)$ (Fig. 2). The few damaged stations in 1990 were limited to the zones easily reachable from inland, such as the rocks near Torre Ovo, Campomarino and Torre Lapillo.

Sector C. This is another area subjected to heavy date mussel fishery. There was a nonsignificant difference between the $D_{\mathrm{w}}$ values of this sector in 1990 and 1992 (0.407 vs 0.416) (Fig 2).

Torre Lapillo to Torre S. Isidoro (5 transects): In this area, which has been proposed for the establishment of a National Marine Park (Porto Cesareo), all rocky coasts were heavily damaged during both surveys with $D_{\mathrm{w}}$ values of transects ranging from 0.321 to 0.929 in 1990 and from 0.629 to 0.964 in 1992 . Also, the intertidal rocks were destroyed. Fragments of rocks still covered by benthic organisms were observed in both years at many damaged stations, indicating recent dismantling activities.

Torre San Isidoro to Gallipoli (14 transects in 1990 and 13 in 1992): Many transects along this mainly rocky coast had medium damage; at Torre Alto Lido the bottom had abundant large bare patches (damage value 6) between 1 and $7 \mathrm{~m}$ depth. Porto Selvaggio, a site recently proposed for the establishment of a
National Marine Park, showed evident signs of date mussel fisheries. The $D_{w}$ value of both surveys was about 0.30 .

Sector D. Torre del Pizzo to Capo Santa Maria di Lcuca (1 1 transects in 1990 and 17 in 1992): The coast is low and the rocky bottoms are not steep. Rocks with date mussels were observed from Torre del Pizzo to the Secche di Ugento, whereas date mussels were less frequent from Torre Mozza to Capo Santa Maria di Leuca.

In this sector the existence of damage at the bottom greatly increased from the first survey $\left(D_{w}=0.194\right)$ to the second one $\left(D_{w}=0.296\right)$ (Fig. 2); however, the increase was not statistically significant by the Student's $t$-test $(p>0.05)$, probably due to great differences in the number of observations in the 2 surveys (14 in 1990 vs 55 in 1992).

Sector E. $D_{w}$ values were lower in 1990 than in 1992, but the difference was not statistically significant (0.319 vs 0.337; Student's $t$-test; $\mathrm{p}>0.05$ ) (Fig. 2)

Capo Santa Maria di Leuca to Porto Badisco (13 transects in 1990 and 14 in 1992): The coast is rocky and steep. The calcareous rocks are more compact (dolomitic rock) than in other parts of the coast. Damage was mostly represented by abundant small bare patches, probably resulting from the activity of nonprofessional divers, observed during both surveys while collecting date mussels for their own family consumption. In 1992 damage was high near the Zinzulusa caves, where the rocky shores were completely bare (damage value 7 ) from the surface to the beginning of the coralligenous facies ( 9 to $10 \mathrm{~m}$ depth). This part of the Penisola Salentina has also been proposed as a National Marine Park due to the beauty of the communities inhabiting its rocky cliffs, characterized by many marine caves.

S. Emiliano Island to Torre dell'Orso 6 transects in 1990 and 8 in 1992): The coast is rocky and rather steep, only north of Otranto is its inclination sharply reduced. In almost all transects the rocks showed medium damage between 1 and $7 \mathrm{~m}$ depth. In the 
proximity of the Club Méditerranée (Otranto) large bare patches (over $1 \mathrm{~m}^{2}$ ) were observed.

Sector F. This last sector was surveyed in 1992 only. All transects revealed an intense fishery $\left(D_{w}=0.373\right)$ (Fig. 2) and signs of collection were recent in $45 \%$ of damaged stations.

Torre dell'Orso to Torre Specchia Ruggieri (4 transects): Along this stretch of coast the bottom slowly declines, with few vertical walls. However, all sites were more or less damaged $\left(D_{w}=0.266\right)$, even with isolated patches (damage value 2 or 3 ). In some stations, rocks showed recent damage.

Torre Specchia Ruggieri to Capo Torre Cavallo ( 7 transects): This coast is mainly sandy, with boulders or isolated rocks $\left(D_{\mathrm{w}}=0.57\right)$.

Brindisi (2 transects): Two transects near the harbour of Brindisi (Pedagne Islands and the outer lighthouse) showed medium damage $\left(D_{w}=0.429\right)$. The presence of military plants did not discourage date mussel fishermen even within 'no entrance' areas.

Torre Grande Nord to Punta Penne (3 transects): Bottoms were heavily destroyed: $D_{w}$ was 0.837 because many stations were entirely desertified. None of the damage was recent, but signs of recolonization were apparent at the shallower stations only.

Torre Testa to Torre S. Sabina ( 7 transects): Bottoms are almost flat and slowly declining. Isolated bare patches (damage value 1 and 2) were present near the few 'steps' of the bottom $\left(D_{w}=0.333\right)$.

\section{Trends of increased damage}

The curve resulting from the regression of damage change (as the difference between $D_{w}$ values of 1992 and those of 1990) against initial damage (i.e. the $D_{w}$ values in 1990) in sectors $A$ to $E$ at 2 depth ranges (Fig. 6) shows that damage did not increase at sites were the $D_{w}$ values were higher than 0.4 to 0.5 .

\section{DISCUSSION}

The surveys showed effects of date mussel collection along the whole inspected coast where the molluscs are available (i.e. rocky coasts). In spite of the increasing control activity by local authorities, the destruction of rocky bottoms did not slow down in the period 1990 to 1992 . On the contrary, this activity seems to have increased. During the first survey, major damage was observed in sectors $\mathrm{A}, \mathrm{C}$ and $\mathrm{E}$, where major towns and tourist villages are located. In these sectors, signs of this destructive activity were observed at every depth from the surface to $10 \mathrm{~m}$ depth. In 1992, sectors $\mathrm{A}$ and $C$ were not significantly more damaged than in 1990 ,

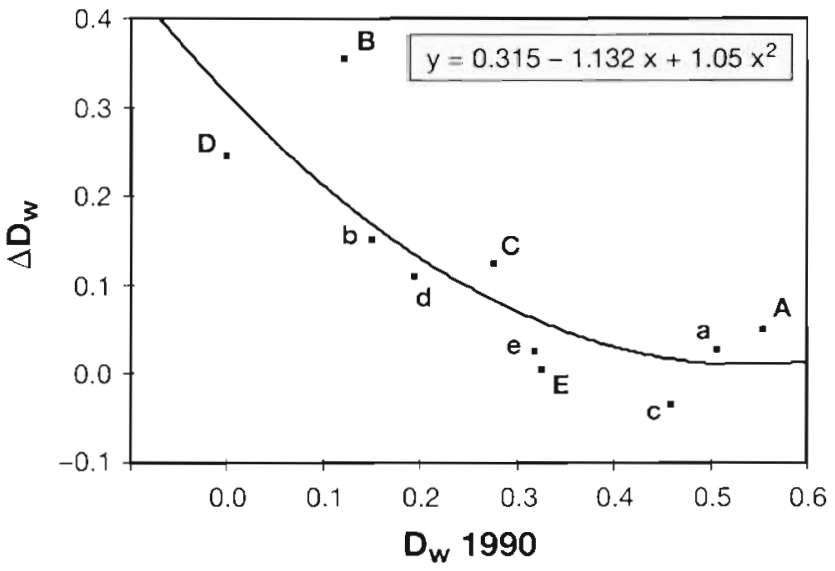

Fig. 6. Trends of increased damage from 1990 to 1992 in 2 depth ranges $\left(\mathrm{p}<0.05 ; \mathrm{R}^{2}=67.2 \%\right)$. Letters represent sectors as in Fig. 2: lower case 0 to $5 \mathrm{~m}$, upper case 5 to $10 \mathrm{~m}$. $\Delta D_{\mathrm{w}}=$ difference between $D_{\mathrm{w}}$ values for 1992 and 1990

while the proportion of damaged coast significantly increased in sectors B and D. Along these stretches of coast, which previously showed low damage mainly affecting shallower bottoms, the highest $D_{w}$ increases were recorded. This suggests that the fishery for Lithophaga lithophaga is expanding from already overexploited areas to less-exploited ones. Sector E seems to be damaged mainly by nonprofessional collectors, since it is characterized by small bare patches. In contrast, the other Ionian sectors seem to be affected mainly by the activity of professional collectors. They operate progressively, exploiting a site until a given spot becomes unprofitable. Starting from rocks within the first $5 \mathrm{~m}$, a depth range in which date mussels are more abundant and SCUBA diving is possible with no time limits, the desertification caused by this activity continues to affect deeper rocks and, then, neighbouring areas. Also, the damage observed in sector $F$ (the only one in the Adriatic Sea), with vast barren areas even on the deeper bottoms, seems to be due to the activity of professional collectors, and this is in accordance with the fact that the Brindisi coast is a traditional date mussel fishery area. However, damage by nonprofessional collectors is sharply increasing because more and more people are collecting date mussels. During low tides, people dismantle the exposed rocks with hammer and chisel, suggesting that date mussel collection is also becoming popular for nondivers.

The significant 1990 to 1992 increase in stations with not-recent damage shows that scars inflicted on rocky shores did not 'heal'. Sea urchin grazing possibly plays a central role in preventing the recolonization of bare areas and its impact is also being investigated with caging experiments. The absence of a dense covering 
of the substrata apparently offers good feeding opportunities to sea urchins, which might feed unselectively on newly settled organisms, thus acting as a major disturbance.

Due to the extremely low growth rate of date mussels and to the failure of recruitment, possibly caused by sea urchin grazing, both Lithophaga and benthic communities can be considered as nonrenewable resources. Future rates of damage to this coast can be envisaged as shown in Fig. 6, reporting the further possible damage at an already damaged bottom. Some sectors (i.e. A, C and F ) are already overexploited, having reached the 'plateau' of $D_{\mathrm{w}}$ values over 0.4 to 0.5. Kingsford et al. (1991) considered humans as predators on rocky reefs, and such a comparison is possible also for date mussel collectors. Predation by date mussel fishermen involves exploitation of a resource patch of limited size and, by applying the theory of optimal foraging, it could be assumed that, once a given portion of the available resource is consumed, they would have 2 possibilities: a drastic reduction of the fishing effort (in number of collectors) and/or a change in the exploited area, for example lessexploited stretches of coast such as sectors $B$ and $D$, or even Greece or Albania (where, as personally communicated by local colleagues, Italian collectors of Lithophaga are already operating). But there is also a third possibility: predators can 'evolve' their techniques to increase their efficiency. In fact, exploited areas are already characterized by a scattered distribution of date mussel patches, so that a fisherman has to move continuously from one patch to another, with a great loss of energy due to increased searching. Since 1991, however, professional date mussel fishermen have been using small underwater vehicles, thus reducing the searching effort and further increasing exploitation of easily accessible sites. Of course, such a rapid 'evolution' of the predator is not followed by an equally rapid evolution of the prey (and of its environment) which, therefore, is in danger of local extinction. If predator behaviour followed the predictions in Fig. 6 , date mussel fisheries should stop at heavily damaged sites. But, our recent observations showed that 'technologically evolved' predators still utilize the already reduced resources.

Date mussel fisheries, possibly followed by sea urchin grazing, are rapidly transforming hundreds of kilometres of the Salento shallow rocky coasts into a desert, and it is possible that in a short time this destructive activity will affect other portions of the Mediterranean coast. The enforcement of the laws

This article was submitted to the editor prohibiting such fishing activity is urgent, as is the institution of multiple marine parks along the Salento peninsula, so as to increase the possibility of recovery of damaged coasts

Acknowledgements. This paper was carried out with contributions from MURST ( $40 \%$ and $60 \%$ programs). We thank A. Giangrande, C. Caroppo, G. Grilli, M. Imperatrice, A. Panarese, M. R. Piccinni, R. Pollicoro, M. Presicce, C. Rainone, F. Rubino, O. D. Saracino, E. Sbenaglia, F. Tucci and the crew of the 'A. Cerruti' (E. Guida and D. Barbarino) for helping during field work, and $M$. Fanelli for helping with statistical treatment of data.

\section{LITERATURE CITED}

Cuccu, D., Campisi, S., Addis, P., Lenza, I., Stefani, M. (1994). Prime osservazioni sulla distribuzione di Lithophaga lithophaga (L.) (Bivalvia Mytilidae) lungo le coste sarde. Mar. Biol. Medit. 1(1): in press

Elner, R. W., Vadas, R. L. Sr (1990). Inference in ecology: the sea urchin phenomenon in the Northwestern Atlantic. Am. Nat. 136: 108-125

Fisher, W. Bauchot, M.-L., Schneider, M. (eds.) (1987). Fiches FAO d'identification des espèces pour les besoins de la pêche (Révision 1). Méditerranée et Mer Noire, Zone de Pêche 37. Vol. 1, Végétaux et invertébrés. FAO, Rome

Hawkins, J. P., Roberts, C. M. (1993). Effects of recreational SCUBA diving on coral reefs: trampling on reef-flat communities. J. appl. Ecol. 30: 25-30

Hrs-Brenko, M., Zavodnik, D., Zahtila, E. (1991). The date shell Lithophaga lithophaga Linnaeus, and its habitat calls for protection in the Adriatic Sea. In: Boudouresque, C. F., Avon, M., Gravez, V. (eds.) Les espèces marines à protéger en Méditerranée. GIS Posidonie, Marseilles, p. $151-158$

Kingsford, M. J., Underwood, A. J., Kennelly, S. J. (1991). Humans as predators on rocky reefs in New South Wales, Australia. Mar. Ecol. Prog. Ser. 72: 1-14

Kleeman, K. H. (1973). Der Gesteinsabbau durch Ätzmuscheln an Kalkküsten. Oecologia 13: 377-395

Kleernan, K. H. (1974). Raumkonkurrenz bei Ätzmuscheln. Mar. Biol. 26: 361-364

Morton, B., Scott, P. J. B. (1980). Morphological and functional. specializations of the shell, musculature and pallial glands in the Lithophaginae (Mollusca: Bivalvia). J Zool., Lond. 192: $179-203$

Pierotti, P., Lo Russo, R., Sivieri Buggiani, S. (1966). Il dattero di mare, Lithodomus lithophagus, nel Golfo della Spezia. Ann. Fac. Med. vet. Univ. Pisa 18: 157-174

Russo, G. F., Cicogna, F (1991). The date mussel (Lithophaga lithophaga), a 'case' in the gulf of Naples. In: Boudouresque, C. F., Avon, M.. Gravez, V. (eds.) Les espèces marines à protéger en Méditerranée. GIS Posidonie, Marseilles, p. 141-150

Russo, G. F. Cicogna, F. (1992). Il dattero di mare, Lithophaga lithophaga e gli effetti distruttivi della sua pesca sull'ambiente marino costiero: problemi e prospettive. Boll. Mus. Ist. biol. Univ. Genova 56/57: 165-194

Manuscript first received: December 21, 1993

Revised version accepted: March 23, 1994 